\title{
DA SUPERPROTEÇÃO AO ESTIGMA: RELAÇÕES FAMILIARES DE PESSOAS COM ÚLCERA DE PERNA E DOENÇA FALCIFORME
}

\author{
FROM OVERPROTECTION TO STIGMA: \\ FAMILY RELATIONS OF PEOPLE WITH LEG \\ ULCER AND SICKLE CELL DISEASE
}

\section{DE LA SOBREPROTECCIÓN AL ESTIGMA: RELACIONES FAMILIARES DE LAS PERSONAS CON ÚLCERA DE LA PIERNA Y ENFERMEDAD FALCIFORME}

\author{
Luana Santana Brito ${ }^{1}$ \\ Evanilda Souza de Santana Carvalho ${ }^{2}$ \\ Sheila Santa Bárbara Cerqueira ${ }^{3}$ \\ Luciano Marques dos Santos ${ }^{4}$
}

\begin{abstract}
Como citar este artigo: Brito LS, Carvalho ESS, Cerqueira SSB, Santos LM. Da superproteção ao estigma: relações familiares de pessoas com úlcera de perna e doença falciforme. Rev baiana enferm. 2021:35:e37793.

Objetivo: apreender as percepções dos adoecidos com úlceras de perna e doença falciforme acerca das relações familiares no adoecimento crônico. Método: estudo qualitativo exploratório do tipo descritivo com cinco pessoas com úlceras de pernas secundárias à doença falciforme. Os dados foram obtidos em entrevistas e submetidos à análise temática. Resultados: pessoas com doença falciforme e úlceras percebem a dedicação e o cuidado recebidos dos familiares para manutenção de uma rotina de tratamento, mas avaliam que esses familiares superprotegem e limitam a condição de viver devido ao medo da morte. Em contrapartida, as pessoas com essa doença são maltratadas por familiares que não compreendem as limitações da doença. Conclusão: os adoecidos com úlceras de perna e doença falciforme atribuem importância aos familiares no enfrentamento das adversidades promovidas pela doença, bem como destacam que a família é fonte de maus-tratos, que reforçam sentimentos de inutilidade, pela dependência de cuidados e discriminação sofrida.
\end{abstract}

Descritores: Família. Anemia Falciforme. Úlcera da Perna. Estigma Social. Doença Crônica.

Objective: to grasp the perceptions of the sick with leg ulcers and sickle cell disease about family relationships in chronic illness. Method: exploratory, qualitative, descriptive-type study with five people with leg ulcers secondary to sickle cell disease. Data were obtained in interviews and submitted to thematic analysis. Results: people with sickle cell disease and ulcers perceive the dedication and care received from family members to maintain a treatment routine, but assess that these family members overprotect and limit their living condition due to fear of death. On the other hand, people with this disease are mistreated by family members who do not understand the limitations caused by the

\footnotetext{
Enfermeira. Universidade Estadual de Feira de Santana. Feira de Santana, Bahia, Brasil. luanasbrito@hotmail.com. https://orcid.org/0000-0002-7|88-5497.

Enfermeira. Mestre em Enfermagem. Doutora em Enfermagem. Docente da Universidade Estadual de Feira de Santana. Feira de Santana, Bahia, Brasil. https://orcid.org/0000-0003-4564-0768

Enfermeira. Mestre em Saúde Coletiva. Universidade Estadual de Feira de Santana. Feira de Santana, Bahia, Brasil. https://orcid.org/0000-0002-3557-7200

Enfermeiro. Mestre em Enfermagem. Docente Assistente da Universidade Estadual de Feira de Santana. Feira de Santana, Bahia, Brasil. https://orcid.org/0000-000 I$7866-6353$
} 
disease. Conclusion: the sick with leg ulcers and sickle cell disease attribute importance to family members in coping with the adversities promoted by the disease, as well as highlight that the family is a source of ill-treatment, which reinforces feelings of uselessness, due to the dependence on care and discrimination suffered.

Descriptors: Family. Anemia, Sickle Cell. Leg Ulcer. Social Stigma. Chronic Disease.

Objetivo: detener las percepciones de los enfermos con úlceras de la pierna y enfermedad falciforme sobre las relaciones familiares en enfermedades crónicas. Método: estudio cualitativo exploratorio de tipo descriptivo con cinco personas con úlceras de la pierna secundaria a la enfermedad falciforme. Los datos se obtuvieron en entrevistas y se sometieron al análisis temático. Resultados: las personas con enfermedad falciforme y úlceras perciben la dedicación y la atención recibida de los miembros de la familia para mantener una rutina de tratamiento, pero evalúan que estos miembros de la familia sobreprotegen y limitan la condición de vivir debido al miedo a la muerte. Por otro lado, las personas con esta enfermedad son maltratadas por familiares que no entienden las limitaciones de la enfermedad. Conclusión: los enfermos con úlcera de la pierna y la enfermedad falciforme conceden importancia a los miembros de la familia para el enfrentamiento de las adversidades promovidas por la enfermedad, así como destacan que la familia es una fuente de malos tratos, que refuerzan los sentimientos de inutilidad, debido a la dependencia de la atención y la discriminación sufrida.

Descriptores: Familia. Anemia de Células Falciformes. Úlcera de la Pierna. Estigma Social. Enfermedad Crónica.

\section{Introdução}

A doença falciforme (DF) é genética e crônica, considerada um problema de saúde pública por ser bastante prevalente no Brasil e no mundo, com alto índice de morbimortalidade consequente a diversas complicações decorrentes da doença $^{(1)}$. O termo DF engloba um grupo de anemias hemolíticas hereditárias que têm em comum a presença de hemoglobina $\mathrm{S}$ ( $\mathrm{Hb} \mathrm{S}$ ) dentro da hemácia. A presença da $\mathrm{Hb} \mathrm{S}$ altera a conformação da hemácia e desencadeia uma série de disfunções orgânicas que vão impactar nas atividades de vida diária dos adoecidos ${ }^{(2)}$.

A DF possui um agravante social pela sua magnitude e transcendência, uma vez que indivíduos com DF, na sua imensa maioria, pertencem às camadas mais desfavorecidas economicamente. Essa situação agrava-se em função das diversas limitações que a doença impõe, como o desemprego e a baixa escolaridade. Associado a isso, a DF foi trazida com o processo de imigração forçada de pessoas escravizadas advindas da África para as colônias portuguesas da América. É mais prevalente em regiões que receberam e predominavam os africanos nesse período.

Estima-se que, no Brasil, existam mais de 8.000 pessoas com anemia falciforme e cerca de 2 milhões de pessoas portadores do gene da $\mathrm{Hb} \mathrm{S}^{(3)}$. A Bahia é o estado com maior número de afrodescendentes e apresenta a maior prevalência da doença no país, atingindo índices de $5,5 \%$ da população ${ }^{(4)}$.

As úlceras de perna são a manifestação cutânea mais comum da DF e pode ser uma condição crônica e debilitante, influenciando negativamente a qualidade de vida ${ }^{(5)}$. Essas lesões bastante dolorosas surgem ainda na juventude. Geralmente tornam-se crônicas e são resistentes às terapias empregadas, com elevadas taxas de recorrência após cicatrização ${ }^{(6)}$.

A pessoa com DF encontra-se numa vivência desencadeante de grande vulnerabilidade psicológica não só por tratar-se de uma doença potencialmente incapacitante, como também porque sua trajetória terapêutica induz, muitas vezes, a alterações estigmatizantes na imagem corporal, como o surgimento de úlceras de perna, que repercutem na autoestima e na identidade dos sujeitos adoecidos. As limitações e repercussões físicas da DF visíveis no corpo podem levar os sujeitos adoecidos a ingressar em um processo estigmatizante. O estigma social é definido como condição do indivíduo que está inabilitado para aceitação social plena ${ }^{(7)}$.

A DF é uma condição que pode gerar diversas alterações na vida das pessoas, com repercussões nas interações sociais, relações conjugais 
e familiares, educação e emprego ${ }^{(9)}$, principalmente quando associada à úlcera de perna ${ }^{(8)}$. As úlceras de perna estão presentes em 8\% a 10\% das pessoas com DF e pacientes homozigotos. Existem relatos de incidência maior de $50 \% \mathrm{em}$ pacientes que residem em áreas tropicais ${ }^{(9)}$.

Conviver com o doente com uma doença crônica e perceber seu sofrimento físico e psíquico permite a reflexão de que esta condição traz uma série de mudanças na vida não apenas do adoecido, mas também de seus familiares que, muitas vezes, não estão preparados para compreender todos os aspectos que envolvem o problema, o que exige estratégias de enfrentamento frente à nova situação ${ }^{(10)}$.

As mudanças nas relações interpessoais dos indivíduos com DF são agravadas quando estes apresentam outra complicação crônica associada à doença de base, como é o caso das úlceras de pernas secundárias à DF. As alterações nas relações familiares podem interferir de forma negativa nas relações interpessoais entre os familiares e ocasionar uma série de complicações tanto para os adoecidos quanto para os familiares. Por isso, torna-se necessário adquirir estratégias de enfrentamento para minimizar essas complicações, bem como intervir de forma positiva no processo de reabilitação do indivíduo que apresenta a condição crônica de saúde.

A DF causa impactos significativos na vida do indivíduo adoecido e de sua família, seja considerando o momento do diagnóstico, seja pelo envolvimento em todo o processo de cuidado ${ }^{(2)}$. As modificações que causam repercussões na relação familiar podem intervir de forma positiva ou negativa no processo de reabilitação do indivíduo. Dessa forma, uma boa relação familiar é de grande importância nas condições em que as pessoas experienciam as doenças crônicas, pois os familiares podem fortalecer a pessoa adoecida para o enfrentamento da doença.

Embora o tema doença falciforme (DF) esteja sendo ascendentemente pesquisado no Brasil, a elevada prevalência da DF, bem como o alto índice de morbimortalidade consequente das complicações impostas pela doença, como citado, são fatores que fomentam a necessidade de compreender como o cotidiano de familiares e pessoas com úlceras de perna secundárias à DF revela-se diariamente. Diante do exposto, a relevância deste estudo manifesta-se pela possibilidade de que o objeto em questão seja discutido no meio acadêmico e científico, a fim de elucidar quais são as dificuldades enfrentadas nas relações familiares no adoecimento crônico pela ótica das pessoas com úlcera secundária à DF, bem como para promoção de práticas de acolhimento na assistência que contemplem o indivíduo nas dimensões biológicas, sociais e psicoemocionais.

A justificativa deste estudo abarca a necessidade de profissionais de Enfermagem compreenderem as relações familiares de pessoas com DF, para fundamentar as ações de cuidado e atitudes comprometidas com o adoecido e sua família, bem como fortalecer os vínculos no processo de cuidar e nas estratégias de enfrentamento.

O objeto de investigação do presente estudo é "Relações familiares de pessoas com úlceras de perna secundárias à DF”. Este estudo parte da seguinte questão: Como as relações familiares no adoecimento crônico são percebidas pelos adoecidos com úlcera secundária à DF?

$\mathrm{O}$ estudo tem como objetivo apreender as percepções dos adoecidos com úlceras de perna e DF acerca das relações familiares no adoecimento crônico.

\section{Método}

Foi desenvolvido um estudo qualitativo, exploratório, do tipo descritivo, em um Centro de Referência ao atendimento de pessoas com DF, localizado no estado da Bahia. Participaram do estudo pessoas que atenderam aos seguintes critérios de inclusão: ser adulto, com diagnóstico de doença falciforme e apresentar úlcera de perna. O critério de exclusão utilizado foi apresentar relato de dor no encontro. Os participantes da amostra foram escolhidos por conveniência, selecionando-se os membros da população mais acessíveis.

A coleta de dados ocorreu no período de outubro a novembro de 2016. A aproximação 
da pesquisadora com os participantes do estudo ocorreu durante visitas prévias ao serviço de referência, onde foram realizados acompanhamentos dos curativos de úlceras de perna realizados pela enfermeira da unidade. Durante essa aproximação, os participantes foram abordados a respeito do interesse em participar do estudo. $\mathrm{Na}$ oportunidade, foram fornecidas informações acerca dos objetivos, riscos, benefícios e relevância do estudo.

Todos os cinco pacientes que estavam realizando curativos semanalmente na unidade de referência aceitaram tomar parte no estudo, sem recusas. Os encontros foram agendados de acordo com a disponibilidade deles e da primeira autora. A duração média das entrevistas foi de 15 minutos. A primeira autora e pesquisadora, durante o período de coleta de dados, participava do Núcleo de Estudos de Desigualdades em Saúde (NUDES) da Universidade Estadual de Feira de Santana (UEFS) como bolsista de iniciação científica e atualmente é mestranda do Mestrado Profissional em Enfermagem dessa universidade.

A coleta de dados ocorreu mediante aplicação de entrevistas semiestruturadas, gravadas e posteriormente transcritas pela entrevistadora, realizadas em ambiente restrito (consultório de enfermagem da unidade), na presença exclusiva da entrevistadora e do participante.

Aos participantes foi apresentada a oportunidade de escutar, revisar, modificar ou acrescentar conteúdos e/ou quaisquer informações, contudo nenhum deles manifestou desejo de fazê-lo. A saturação teórica do estudo ocorreu quando se identificou que os dados obtidos passaram a apresentar redundância e alcançou-se o objetivo principal do estudo.

Foi realizada previamente uma entrevista, para validar o instrumento de coleta de dados (teste piloto), com o objetivo de ajustar as perguntas e evitar interpretações dúbias, o que poderia comprometer a obtenção de dados fidedignos. No entanto, não foi necessária readequação no decorrer do estudo.

Foi aplicado um roteiro semiestruturado com elementos que permitiram conhecer o perfil sociodemográfico do adoecido e de suas famílias e as seguintes questões norteadoras: Como você vê o relacionamento da família com a pessoa que tem úlcera de perna e DF? Como são as relações familiares com a pessoa adoecida após o surgimento das úlceras secundárias à DF?

Os dados foram submetidos à análise temática reflexiva. Inicialmente, procedeu-se à familiarização, transcrição, leituras e releituras exaustivas do conjunto de dados. Em seguida, fez-se a codificação de aspectos capturados na leitura semântica e conceitual dos dados. Cada código foi revisado, buscando-se a identificar a existência de temas, observar o padrão e a coerência entre os códigos e procedeu-se ao agrupamento. $\mathrm{Na}$ revisão dos temas, buscou-se seu refinamento. Por fim, foram definidos e nomeados os temas e elaborada a escrita dos resultados ${ }^{(11)}$. Não foi utilizado nenhum programa para gerenciar dados. Foram realizados registros em diário de campo quanto às emoções demonstradas pelos participantes durante a coleta de dados.

Visando preservar a identidade dos participantes, neste texto, eles estão identificados pela letra E (entrevistado) seguida de um número indicativo da ordem da entrevista. Exemplo: (E1).

Este estudo foi guiado pelo protocolo de qualidade de estudos qualitativos Consolidated Criteria for Reporting Qualitative Research (COREQ). Quanto aos aspectos éticos, foram seguidas as recomendações da Resolução n. 466/2012 do Conselho Nacional de Saúde em todas as etapas. Este estudo está vinculado ao projeto de pesquisa intitulado "Representações sobre o Corpo e a Doença Falciforme: Repercussões sobre a Vida Cotidiana, o Cuidado e a Sexualidade", aprovado pelo Parecer n. 1.440.239 e Certificado de Apresentação de Apreciação Ética (CAAE) 49493315.3.1001.0053.

\section{Resultados}

Participaram deste estudo cinco pessoas com úlceras de pernas secundárias à DF. As características sociodemográficas analisadas originaram-se dos grupos de variáveis: identificação, sexo, idade, escolaridade e ocupação. Os resultados 
apontaram maior concentração de usuários de 30 a 40 anos de idade; do sexo masculino; de ensino médio incompleto; religião protestante; raça/cor preta. Todos os participantes do estudo encontravam-se desempregados. Os temas apreendidos são apresentados a seguir:

\section{Relações familiares marcadas pelo zelo e pela preocupação}

As pessoas com úlcera de perna e DF vivenciavam manifestações clínicas que impunham uma rígida rotina de cuidados e frequentes visitas às unidades de saúde para manejo da dor, transfusões sanguíneas e consultas, como evidenciado na fala a seguir:

De tanto ver causar sofrimento, noites e noites sem dormir, crises mais crises, internamento. Eu encaro, assim, com muita dificuldade. (E1).

Os participantes percebiam que seus familiares desenvolviam com eles uma relação harmoniosa de cuidado e buscavam ofertar-lhes bem-estar. Essas relações eram marcadas por sentimentos de zelo, preocupação e superproteção por parte dos familiares para com os adoecidos, como evidenciado na fala a seguir:

Minha tia que mora junto comigo fica preocupada e diz: "Ah, por que o 'E3' fica saindo, chega tarde!" Eé normal.(E3).

O estudo mostrou que a relação familiar ajuda no enfrentamento da DF e da úlcera de perna, quando o adoecido recebe cuidados, afeto e atenções e quando ele vê no familiar um apoio para enfrentar as dificuldades encontradas na trajetória do adoecimento. Também ficou evidenciado que os cuidados prestados pelos familiares, como fornecer a alimentação nos horários programados, promover tranquilidade nas crises álgicas e realizar curativos das úlceras de perna, proporcionavam relações familiares consideradas boas para os adoecidos:

O relacionamento é bom. Porque tem todo aquele cuidado. Impede que eu possa fazer qualquer coisa que possa prejudicar ainda mais. Me sustentam. Não permitem que eu trabalhe, faça esforço. Quando eu quero fazer, dizem se cuida e tal. O relacionamento é ótimo! Em geral, é ótimo [...] Mas em casa normalmente já estão acostumados. (E2).

Na minha família não tem problema não, graças à Deus. Todo mundo me trata bem. (E3).
Faz meu suco na bora certinha, minha alimentação, me trata muito direito. Quando eu estou nervoso, sentindo dor, ela me dá carinho, às vezes chora junto comigo nos momentos que estou passando difícil. Ela é a pessoa, é minha mulher e minha familia que eu tenho. Nunca tem preconceito de dizer que vai me deixar, nem nada. Nós vivemos tudo na paz, nós rezamos juntos, nós andamos juntos. Ela não tem preconceito comigo, nunca teve e não tem. (E4).

As atitudes de preocupação e zelo em demasia eram percebidas pelos participantes, que atribuíam tal comportamento dos familiares ao medo da sua morte, principalmente quando na família já houve registro de perda de algum dos membros com a mesma doença, como relatado a seguir:

Assim, é porque eu já tive outros irmãos com anemia falciforme. Eu sou a do meio. Então os dois mais novos já faleceram devido a anemia falciforme [...] desde quando eu era pequena, meus pais sempre ficaram muito alertas, muito preocupados [...] ficam muito tensos. Muito tristes, principalmente minha mãe, que perdeu dois filbos. Minha mãe fica preocupada comigo, por já ter perdido dois filbos. Ela não quer perder mais uma. Aí é essa a preocupação constante. (E2).

Ao mesmo tempo em que o zelo é compreendido pelos adoecidos como manifestações de carinho e cuidado, em outros momentos tais atitudes por parte dos familiares eram percebidas como super proteção que tolhia sua liberdade, impedia-os de tomar decisões importantes, que supostamente lhes trariam satisfação, como assumir trabalho ou sair com amigos. Assim, os cuidados que lhes eram dirigidos pela família motivavam sentimentos contraditórios, ora de satisfação, ora de descontentamento.

\section{Conflitos familiares evidenciavam o estigma e suas consequências}

Um dos problemas que suscitavam conflitos nas relações familiares estava relacionado aos gastos financeiros decorrentes do cuidado da doença e da úlcera de perna. Somava-se a isso as manifestações e complicações da DF, que provocavam limitações de ordem física, impossibilitando-os de trabalhar e contribuir nas despesas financeiras da família, como se pode visualizar nos fragmentos a seguir:

[...] às vezes é por eu não poder arrumar minha casa, contribuir com alguma coisa que eu podia. (E1). 
A gente se sente, muitas vezes, impossibilitada de fazer qualquer coisa, se sentir útil [...] te impedindo de fazer certas coisas [...] Ai você fica naquela preocupação se vai atrapalhar. Ai você fica se limitando até arrumar um namorado, casar e tudo. Porque você não vai ser uma pessoa tão ágil como uma pessoa normal. Devido às úlceras, você tem impedimento de fazer muitas coisas, atividade de casa, cuidar de filbo. (E2).

[...] depois eu tive que parar de trabalhar e ficou mais dificil. (E3).

É muito angustiante, assim. Você vive assim angustiante. Te afeta em todas as áreas [...] Eu não tenbo renda, quero arrumar um emprego, dificil arrumar. A gente se sente, muitas vezes, impossibilitada de fazer qualquer coisa, se sentir útil. (E2).

Ai eles acham que possa ser: "Ah, não acho tão dificil ter esse ferimento paralisar desse jeito, tem que mudar, tem que fazer". Ai eu fico assim indignada! (E1).

Desse modo, a falta de compreensão sobre as manifestações clínicas e complicações da DF no corpo do adoecido suscitava conflitos, que muitas vezes se expressavam no descrédito de suas narrativas de dor e cansaço e por meio da cobrança das atividades diárias e responsabilidades que a pessoa adoecida realizava antes do surgimento da úlcera de perna, como se pode observar a seguir:

E eles [familiares], às vezes, entendem e às vezes não entende. Dizem que eu dou meu corpo de mole, que eu me entrego demais, que eu não me levanto. De vez em quando, gera algum problema, alguma contenda, alguma coisa. (E1).

Eles fazem pouco [da doença], acham que eu sinto esse problema porque eu quero. Acho que eles pensam assim, que eu não sei o que passa no juizo deles. Será que eles não pensam assim que um dia eles vão sofrer também? Que não seja dessa maneira, mas seja de outra maneira, que é sofrimento também? (E4).

Meio acanhado no caso é que a bora que a mulher aproveita pra poder pisar no cara, pra desfazer, fica soltando piadinha, desfaz do cara, porque acha que a gente não é capaz por causa do problema, fica naquelas intrigazinha, é, meio chatinhas. (E5).

O depoimento seguinte mostra que a incompreensão dos familiares acerca das limitações provocadas pela doença ao corpo do adoecido confluía para intrigas e contendas nas relações familiares, nas quais se manifestavam o preconceito, críticas e apelidos pejorativos atribuídos por eles:

Minha mãe, meus irmãos, meus tios, que me maltrata muito! Ainda depois de eu casado, sou maltratado por eles. Não todos. Sempre tem um que é diferente dos outro. Aí não me trata com respeito, como eu respeito todo mundo. E quando eu chego lá, eles me tratam dessa maneira, de ladrão, vagabundo, resto da doença, sobejo da morte, mendigo. Ai eu digo: "Será que um dia tu não vai ter um filho ou um parente que tu não pensa isso?" Entrego tudo a Deus e dou as costas. (E4).

Essas vivências culminavam com o sofrimento dos adoecidos, que tendiam a experimentar sentimentos de inutilidade, vergonha e angústia. O sentimento de vergonha foi associado ao fato de a pessoa com DF e úlceras de perna necessitar de ajuda para a realização de alguns cuidados, como trocar o curativo ou preparar a alimentação, como é evidenciado nas seguintes falas:

Às vezes, eu sinto muita vergonha de estar carregando
um ferimento dentro dos meus pés. Tenho vergonba da
minha família, de tudo, da úlcera, da anemia falciforme,
saber que tenho uma doença que não tem cura [...] (E1).

Eu com ela [esposa], ela me trata muito bem, passa minha alimentação muito direito, às vezes eu tenho até vergonha assim do que ela faz comigo. Se for possivel pra ela lavar uma enfermidade, ela lava, ela faz o curativo. Eu me sinto assim, eu digo: "Tem hora que eu sinto vergonha, um pouco de vergonha de sair com você, você tão bem arrumada, tão bonita e eu atrás de você, mancando." Aí ela diz: "Meu filho, nunca pense isso de mim com você." Aí me abraça, me beija, me dá carinho. Aí eu fico com muito orgulbo de viver essa vida que hoje vivo. (E4).

O que mudou é que a gente se sente ainda meio envergonhado para as coisas, não se sente mais à vontade dentro de casa. (E5).

Conflitos familiares em torno do adoecimento crônico de um dos membros eram provocados por mudanças de papéis e pelo desvio de recursos antes destinados à manutenção da família, para custear medicamentos, coberturas, além dos deslocamentos diários às unidades para consultas e curativos. Esses conflitos eram agravados pelo fato de a pessoa com úlcera de perna ser dependente e limitada para o trabalho remunerado e não poder contribuir economicamente com esses gastos.

A forma como eram evidenciados os conflitos e as exigências sobre a pessoa com DF e úlceras de perna sinalizava a existência do estigma relacionado à doença e à ferida que, além de expor a pessoa às pressões contínuas para corresponder a uma expectativa social de normalidade por parte da família, implicava no surgimento de sentimentos e emoções relacionados à desvalorização e adesão à depreciação que lhe era imposta com consequente antecipação do 
estigma revelado no sentimento de vergonha. Tais evidências são constatadas também nas seguintes falas:

E eles [os familiares] não podem aceitar ou ao mesmo tempo não querer aceitar [...] Dizer que aceita e ao mesmo tempo não aceitar [...] (E1).

Toda essa preocupação que você fica se limitando e você até mesmo se exclui, tanto sentimental quanto profissional. (E2).

Chama pra ir num local, num lugar, e a gente não vai; chama pra passear, e a gente não vai, porque está se sentindo mal. Tudo isso muda. (E5).

\section{Discussão}

O apoio da família é essencial para a resolução de dificuldades e problemas encontrados durante o adoecimento crônico. No entanto, este estudo evidenciou também que o excesso de cuidado pode provocar nos sujeitos adoecidos a sensação de perda de liberdade e autonomia para gerir suas próprias vidas. Os indíviduos com DF desde a infância são superprotegidos pelos pais e cuidadores por meio de demonstrações de amor ou preocupação, devido à falta de conhecimento acerca da doença ou por não compreenderem os aspectos da enfermidade $^{(12)}$. Neste estudo, também foi identificado que esse cuidado e zelo, por parte dos familiares, repercutia no bem-estar dos sujeitos adoecidos.

Pessoas com úlceras de perna secundárias à DF sofrem o impacto psicossocial dessas feridas crônicas em seu cotidiano. A dor ocasionada pela úlcera é um fator que interfere na função física, sendo por vezes evitada ou restrita, e também nas relações sociais, pois a dor pode impossibilitar a socialização do indivíduo, impedindo-o de praticar esportes, lazer e ida a eventos ${ }^{(13)}$.

Ao relatarem o excesso de zelo por parte dos familiares, os participantes revelavam seu desconforto. Os comportamentos de vigilância dos familiares são construídos na experiência com o adoecido, ao assistir as complicações que colocam sua vida em risco. O temor da morte é muito reforçado no imaginário da família, devido ao grande risco apresentado pela DF, nos primeiros anos de vida da criança ${ }^{(14)}$.
A superproteção dirigida pelos familiares aos adoecidos surge como uma atitude ancorada no medo da perda, por expectativa de morte ou experiência de perdas anteriores. Corrobora este achado estudo que identificou necessidades emocionais apresentadas pelas famílias de pessoas com DF, representadas pelo temor da morte, permanecendo sempre em estado de alerta, de forma semelhante ao observado no contexto de outras doença crônicas ${ }^{(2)}$.

A percepção da perda da liberdade pode provocar insatisfação e motivar as pessoas adoecidas a transgredirem normas, para se sentirem livres, ou a reforçarem o sentimento de diferença e se retraírem, assumindo a autoexclusão. Pessoas jovens acometidas por esta complicação têm uma grande dificuldade de aderir ao tratamento, bem como ao convívio social, refletindo a perda da autoestima, diminuição da atividade sexual, entre outros aspectos ${ }^{(15)}$.

O surgimento das úlceras compromete significativamente a qualidade de vida do sujeito acometido, em decorrência da redução da força muscular, da capacidade funcional e da amplitude de movimento ${ }^{(16)}$. Neste estudo, identificou-se que esses desafios tiveram como consequência abandono do emprego e déficit de lazer, despertando, nos adoecidos, o sentimento de inutilidade para fazer frente às demandas sociais e econômicas da unidade familiar.

As dificuldades do cotidiano e os eventuais conflitos são agravados pelo processo de adoecimento que acarreta, para os familiares, uma significativa sobrecarga de cuidados e provoca, nos adoecidos, sentimentos de menos valia, de culpa, de insegurança, de medo, de pessimismo e de isolamento social ${ }^{(17)}$. O curso da DF, embora varie de pessoa para pessoa, muitas vezes é perturbador e pode ser estressante para toda a família ${ }^{(18)}$.

Neste estudo, os conflitos familiares podiam estar relacionados aos gastos financeiros decorrentes do processo de adoecimento, em detrimento da destinação dos recursos para a manutenção da família, bem como ao fato de a pessoa com úlcera de perna secundária à DF possuir limitações que repercutiam na sua 
capacidade para a função laboral. Neste aspecto, corrobora resultado de estudo em que os familiares também se encontravam sobrecarregados financeira e emocionalmente ${ }^{(18)}$.

Outro aspecto presente na DF é o estigma, que envolve um tipo de rotulagem de consequências negativas para os indivíduos sobre os quais recai a condenação ${ }^{(19)}$. Neste estudo, o descrédito relatado pelo adoecido foi mencionado como falta de compreensão. Pessoas com DF têm suas experiências de dor desvalorizadas ou desacreditadas por outras pessoas, que lhes atribuem rótulos de fracos, preguiçosos e que fingem estar doentes ${ }^{(20-21)}$.

A presença da úlcera fere a autoimagem, evoca o sentimento de vergonha e afeta a qualidade de vida dos indivíduos, exigindo maiores cuidados familiares e maior cobertura multiprofissional ${ }^{(15,22)}$. No presente estudo, o sentimento de vergonha foi acionado também em razão dos adoecidos necessitarem de ajuda para a realização de cuidados diários, como a troca de curativos. Existiu também maior cobrança por parte dos familiares acerca do cumprimento de atividades diárias pelas pessoas com DF devido ao desconhecimento sobre as consequências da doença.

Neste estudo, identificou-se que, durante os conflitos, emergiram discriminação, atitudes de depreciação, aplicação de apelidos pejorativos e xingamentos proferidos pelos próprios familiares, o que se configura como aplicação de estigma $^{(23)}$. Pessoas com DF são tratadas como se tivessem uma deficiência física ou cognitiva, o que implica na incapacidade de atingir objetivos e marcos de vida, bem como sofrem também experiências estigmatizantes em relacionamentos íntimos, devido às complicações da DF, como dor, priapismo e puberdade tardia, que prejudica sua sexualidade ${ }^{(19)}$.

O estigma relacionado à saúde tem se tornado, cada vez mais, um importante problema de saúde pública que tem recebido atenção, à medida que a estigmatização aumenta a carga de indivíduos e famílias afetadas, em especial quando se trata da $\mathrm{DF}^{(24)}$. Seja no contexto familiar, seja nos serviços de saúde, as pessoas que têm DF podem ser estigmatizadas por diversas razões, tais como a raça, estado de doença, status socioeconômico, atraso no crescimento e puberdade e/ou dor crônica e aguda que demandam tratamento com opioides $^{(21)}$. Quando a ferida surge, a soma das violências sofridas e as modificações corporais podem conduzir as pessoas à raiva própria de processos de luto. Nessa fase, os comportamentos agressivos tendem a aflorar e ser dirigidos tanto aos familiares e às pessoas próximas quanto aos trabalhadores de saúde ${ }^{(25)}$.

O sentimento de inutilidade é reforçado neste estudo com a falta de atividade produtiva, de emprego e de escassas condições de contribuir financeiramente com os próprios cuidados. Acredita-se que seja necessária a criação de políticas públicas com a finalidade de reduzir as dificuldades no enfrentamento da doença, por meio de acompanhamento social e psicológico, de modo a incluir pessoas com DF no mercado de trabalho, como, por exemplo, por meio de cotas de emprego.

Este é um dos poucos estudos com a finalidade de examinar as percepções de pessoas com DF e úlceras de perna acerca das relações familiares. Neste sentido, os resultados poderão contribuir para suscitar novos estudos, além de favorecer o debate sobre o alcance das medidas de cuidados e educação acerca da doença falciforme, de modo a incluir os familiares, fortalecer a rede de cuidados e evitar o estigma nas interações familiares.

O quantitativo reduzido de participantes com DF e úlceras de perna, que realizavam curativos semanalmente no centro de referência, pode configurar-se numa possível limitação deste estudo e não permitir generalizações. Além disso, uma amostra maior poderia revelar outros temas e aspectos da interação familiar. Contudo, o uso de entrevistas face a face de maneira aprofundada e os recursos de análise adotados permitiram alcançar os objetivos e a compreensão sobre o fenômeno explorado.

\section{Conclusão}

Este estudo evidenciou que os adoecidos atribuem importância aos familiares para $\mathrm{O}$ 
enfrentamento das adversidades promovidas pela doença, na medida em que o cuidado recebido contribui para que mantenham uma rotina de tratamento, mas também os limitam para as atividades de lazer com atitudes de superproteção.

Por outro lado, ao mesmo tempo, destaca que a família é fonte de maus-tratos, quando não compreende as limitações físicas impostas pela doença, o que leva os adoecidos a se sentirem desconfortáveis no ambiente familiar e a alimentarem sentimentos de inutilidade, reforçados pela dependência de cuidados e discriminação sofrida.

Este estudo contribui para o campo teórico e prático do cuidado de enfermagem, ao oferecer elementos que justifiquem maior inclusão dos adoecidos no próprio cuidado, articulação da rede de apoio para redução da sobrecarga do cuidado e educação em saúde extensiva à família, com vistas a minimizar o desconhecimento da doença e suas manifestações clínicas, além de fornecer orientações para prevenção de incapacidades psicológicas e sociais decorrentes da doença e da sua cronicidade.

\section{Colaborações:}

1 - concepção, projeto, análise e interpretação dos dados: Luana Santana Brito e Evanilda Souza de Santana Carvalho;

2 - redação do artigo e revisão crítica relevante do conteúdo intelectual: Luana Santana Brito, Sheila Santa Bárbara Cerqueira e Luciano Marques dos Santos;

3 - aprovação final da versão a ser publicada: Luana Santana Brito e Evanilda Souza de Santana Carvalho.

\section{Referências}

1. Ataíde CA, Ricas J. O diagnóstico das crianças com doença falciforme: desafios e perspectivas de enfrentamento. Interfaces Científicas - Saúde e Ambiente. 2016;4(2):19-28. DOI: 10.17564/ 2316-3798.2016v4n2p19-28

2. Guimarães TMR, Miranda WL, Tavares MMF. O cotidiano das famílias de crianças e adolescentes portadores de anemia falciforme. Rev Bras
Hematol Hemoter. 2009;31(1):9-14. DOI: 10.1590/ S1516-84842009005000002

3. Cesar P. Caracterização clínica e demográfica de pacientes com doença falciforme acompanhados na fundaçăo hospitalar de hematologia e hemoterapia do Amazonas - HEMOAM [dissertação]. Manaus (AM): Universidade do Estado do Amazonas; 2017.

4. Silva LPA, Vila Nova C, Lucena R. Anemia falciforme e surdez infanto-juvenil: revisão da literatura. Braz j otorhinolaryngol. 2012;78(1):126-31. DOI: http://dx.doi.org/10.1590/S1808-8694201200 0100020

5. Umeh IN, Ajehba B, Buscetta AJ, Abdallah EK, Minniti CP, Bonham VL. The Psychosocial Impact of Leg Ulcers in Patients With Sickle Cell Disease: I Don't Want Them to Know My Little Secret. PLoS One. 2017;12(10):e0186270. DOI: 10.1371/ journal.pone.0186270. 2017

6. Brasil. Ministério da Saúde. Secretaria de Atenção à Saúde. Departamento de Atenção Especializada. Doença falciforme. Úlceras: prevenção e tratamento [Internet]. Brasília (DF); 2012 [cited 2020 Jul 20]. Available from: http://bvsms.saude. gov.br/bvs/publicacoes/doenca_falciforme_ ulceras_prevencao_tratamento.pdf

7. Goffman E. Estigma: notas sobre a manipulação da identidade deteriorada. Rio de Janeiro: LTC; 1981.

8. Santos LA, Santos DSS. Repercussões da doença falciforme e o autocuidado no cotidiano do adolescente: revisão bibliográfica. Rev Bras Saúde Funcional. 2016 [cited 2020 Jun 22];1(3):1-10. Available from: http://www.seeradventista.com.br/ojs3/index.php/RBSF/article/ view/827/644

9. Martins A, Moreira DG, Nascimento EM, Soares E. O autocuidado para o tratamento de úlcera de perna falciforme: orientações de enfermagem. Esc Anna Nery. 2013;17(4):755-63. DOI: https:// doi.org/10.5935/1414-8145.20130021

10. Waidman MAP, Rocha SC, Correa JL, Brischiliari A, Marcon SS. O cotidiano do indivíduo com ferida crônica e sua saúde mental. Texto contexto-enferm. 2011;20(4):691-9. DOI: 10.1590/S010407072011000400007

11. Clark V, Braun V. Using thematic analysis in counselling and psychotherapy research: A critical reflection. Couns Psychother Res. 2018;18(2):107-10. DOI: https://doi.org/10.1002/ capr.12165 
12. Jenerette CM, Lauderdale G. Successful Aging with Sickle Cell Disease: Using Qualitative Methods to Inform Theory. J Theory Constr Test [Internet]. 2008 [cited 2020 Jul 22];12(1):16-24. Available from: https://www.ncbi.nlm.nih.gov/pmc/articles/ PMC2762231/

13. Gomes ILV, Campos DB, Custódio LL, Oliveira RS, organizadoras. Doença falciforme: saberes e práticas do cuidado integral na Rede de Atenção à Saúde [Internet]. Fortaleza: EdUECE; 2019 [cited 2020 Jul 15]. Available from: http:// www.uece.br/eduece/dmdocuments/Doenca falciforme_EDUECE_2019.pdf

14. Ataíde CA, Ricas J. O enfrentamento do diagnóstico da doença falciforme: Desafios e perspectivas vivenciadas pela família. Scientia Plena. 2017;13(5):1-10. DOI: 10.14808/sci.plena. 2017.059908

15. Lacerda FKL, Carvalho ESS, Araújo EM, Miranda NBA, Dias ALA, Almeida TA. Mulheres com anemia falciforme (con)vivendo com as úlceras de perna e a dor. Rev enferm UFPE. 2014;8(7):2054-60. DOI: 10.5205/reuol. 5963-51246-1-RV.0807201429

16. Lacerda FKL, Ferreira SL, Nascimento EL, Costa DO, Cordeiro RC. Déficits de autocuidado em mulheres com úlceras de perna e doença falciforme. Rev bras enferm. 2019;72(3):78-85. DOI: 10.1590/0034-7167-2018-0005

17. Ataíde CA. A educação em saúde enquanto dispositivo para enfrentamento do diagnóstico da doença falciforme. Educon [Internet]. 2016 [cited 2020 Jul 26];10(1):1-12. Available from: https://ri.ufs.br/bitstream/riufs/8969/12/A_ educacao_em_saude_enquanto_dispositivo_para_ enfrentamento_do_diagnostico.pdf

18. Gold JI, Treadwell M, Weissman L, Vichinsky E. An expanded Transactional Stress and Coping Model for siblings of children with sickle cell disease: family functioning and sibling coping, self-efficacy and perceived social support. Child Care Health Dev. 2008;34(4):491-502. DOI: https:// doi.org/10.1111/j.1365-2214.2008.00810.x

19. Bulgin D, Tanabe P, Jenerette C. Stigma of Sickle Cell Disease: A Systematic Review. Issues Ment Health Nurs. 2018;39(8):675-86. DOI: https://doi. org/10.1080/01612840.2018.1443530

20. Ola BA, Yates SJ, Dyson SM. Living with sickle cell disease and depression in Lagos, Nigeria: A mixed methods study. Soc Sci Med. 2016;161:27-36. DOI: 10.1016/j.socscimed.2016.05.029

21. Bulgin D, Tanabe P, Jenerette C. Stigma of Sickle Cell Disease: A Systematic Review. Issues Ment Health Nurs. 2018;39(8):675-86. DOI: https://doi. org/10.1080/01612840.2018.1443530

22. Barberino IA, Coelho TO, Duque BC, Silva EC, Rocha RM. Autoimagem e estigma social na doença falciforme: uma revisão integrativa. Rev Eletrôn Acervo Saúde. 2019;11(8):1-7. DOI: 10.25248/reas. e530.2019

23. Cerqueira SSB, Brito LS, Freitas KS, Jenerette CM, Carvalho ESS. Translation and transcultural adaptation of sickle cell disease health-related stigma scale for the brazilian context. Rev baiana enferm. 2019;33:e34572. DOI: https://doi. org/10.18471/rbe.v33.34572

24. Jenerette CM, Brewer C. Health-related stigma in young adults with sickle cell disease. J Natl Med Assoc. 2010;102(11):1050-5. DOI: https://doi. org/10.1016/s0027-9684(15)30732-x

25. Oliveira AL, Carvalho ESS, Rodrigues GRS. Expression of grief in women with chronic wounds in lower limb. Rev baiana enferm. 2017;31(1):e20439. DOI: https://doi.org/10.18471/ rbe.v31i1.20439

Recebido: 2 de setembro de 2020

Aprovado: 5 de outubro de 2020

Publicado: 23 de novembro de 2020

A Revista Baiana de Enfermagem utiliza a Licença Creative Commons - Atribuição-NãoComercial 4.0 Internacional. https://creativecommons.org/licenses/by-nc/4.0/

Este artigo é de acesso aberto distribuído sob os termos da Licença Creative Commons (CC BY-NC). Esta licença permite que outros remixem, adaptem e criem a partir do seu trabalho para fins não comerciais. Embora os novos trabalhos tenham de lhe atribuir o devido crédito e não possam ser usados para fins comerciais, os usuários não têm de licenciar esses trabalhos derivados sob os mesmos termos. 